Scientia Agricola

http://dx.doi.org/10.1590/0103-9016-2015-0218

\title{
Interspecific hybrids between Paspalum plicatulum and $P$. oteroi: a key tool for
}

\section{forage breeding}

\author{
Patricia Elda Novo ${ }^{1}$, José Francisco Montenegro Valls ${ }^{3}$, Florencia Galdeano ${ }^{1,2}$, Ana Isabel Honfi ${ }^{4}$, Francisco Espinoza ${ }^{1,2 *}$, Camilo \\ Luis Quarin ${ }^{1,2}$
}

\author{
'Botanical Institute of the Northeast, Juan Bautista Cabral, \\ 2131, P.0. Box 209 - Corrientes - Argentina. \\ 2University of the Northeast/Faculty of Agricultural Sciences, \\ Juan Bautista Cabral, 2131, P.0. Box 209 - Corrientes - \\ Argentina. \\ ${ }^{3}$ Embrapa Genetic Resources \& Biotechnology, Av. W5 \\ Norte, C.P. 02372 - 70770-917 - Brasilia, DF - Brazil. \\ ${ }^{4}$ University of Misiones/Faculty of Exact, Chemical, and \\ Natural Sciences, Rivadavia, 2370 - 3300 - Posadas, \\ Misiones - Argentina. \\ *Corresponding author <espinoza@agr.unne.edu.ar>
}

Edited by: Leonardo Oliveira Medici

Received May 18, 2015

Accepted October 01, 2015
ABSTRACT: Grama-tio-pedro (Paspalum oteroi Swallen) is a rare stoloniferous grass of the Plicatula group of Paspalum, well adapted to continuous grazing in areas subject to seasonal flooding in the Pantanal region, in central western Brazil. The species is a facultative apomictic (asexual reproduction by seed) tetraploid, sporadically cultivated on Pantanal farms, propagated either by cuttings or seed. Due to its potential for extensive cultivation and forage quality, Grama-tiopedro appears as a candidate for genetic improvement within the Plicatula group through plant breeding. We used a colchicine-induced sexual autotetraploid genotype of $P$. plicatulum Michx. to obtain interspecific hybrids using the apomictic species, $P$. oteroi, as pollen donor. The very similar meiotic chromosome behavior observed in both parents, with main quadrivalent and bivalent associations, suggested that $P$. oteroi is a natural autotetraploid. The hybrids showed less irregular meiotic behavior with fewer quadrivalents and more bivalents than either parent. Fertility among interspecific hybrids varied from complete sterility in some of them to seed productions in others that were approximately twice as much as for either parent. The great variability of seed set performance may well be a drastic genetic consequence of joining two homologous chromosome sets of $P$. plicatulum together with two homologous sets of $P$. oteroi that, in turn, have some homeology between them. Most hybrids reproduce by sexual means, thus, they could be used as female parents in backcrosses and in crosses with other species of the Plicatula group for interspecific gene transferring in breeding programs.

Keywords: DNA content, apomixis, fertility, meiosis, reproductive mode

\section{Introduction}

The grass genus Paspalum L. is the most important forage constituent in natural pasturelands in South America. The high number and great diversity of species, the large area covered by Paspalum species in native grasslands, its forage quality and the wide range of ecological adaptability support the importance of the genus for cattle farming business. The group Plicatula, as described by Chase (1929), is a taxonomic informal subgeneric category for genus Paspalum, grouping more than 30 species. Most species of the group are apomictic polyploids, although the number of known multiploid species increases as new data become available. Multiploid species comprise different ploidy levels from the sexual diploid cytotype to apomictic cospecific polyploid (usually tetraploid) cytotypes. Paspalum oteroi Swallen is a rare stoloniferous, sod-forming grass of the Plicatula group, well adapted to continuous grazing in areas subject to seasonal flooding in the Pantanal region in Brazil. Known by the popular name of grama-tio-pedro, its cultivation on Pantanal farms, in paddocks, headquarter lawns, and airstrips, propagated either by cuttings or seed, was reported long ago (Otero, 1937). It is a tetraploid species with $2 \mathrm{n}=40$ chromosomes (Pagliarini et al., 2001). P. oteroi is considered a good native forage grass with great potential for extensive cultivation (Camastri Filho and Costa Junior, 1980; Allem and Valls, 1987). Moreover, its relation with species of the Plicatula group makes $P$. oteroi a good candidate for genetic plant improvement, including crosses with other species of the same group. However, the main obstacle for plant breeding is the total absence of completely sexual individuals within polyploid apomictic populations. This obstacle may be overcome by doubling the number of chromosomes of diploid plants to produce sexual tetraploids (Forbes and Burton, 1961; Sartor et al., 2009). Sexual induced-tetraploid germplasm of $P$. plicatulum is currently available (Sartor et al., 2009) and easily hybridizes with other species of the Plicatula group as pollen donors (Aguilera et al., 2011; Novo et al., 2013). This study aimed to hybridize sexual tetraploid $P$. plicatulum with apomictic tetraploid $P$. oteroi to establish their cytogenetic relationship and to determine the reproductive behavior and fertility of the hybrids in order to explore the possibility of gene exchange in breeding programs of these species.

\section{Materials and Methods}

\section{Plant material and crosses}

The interspecific crosses were made using the 4PT genotype of $P$. plicatulum and the accession of $P$. oteroi bearing the Brazilian plant germplasm code BRA 001503, collected at Corumbá, Mato Grosso do Sul State, Brazil, by Allem and Vieira \# 1332, herbarium voucher deposited at CEN, ICN, MO, NY and UEC herbaria (for herbarium code see http://sweetgum.nybg.org/ih/). Accession 4PT is a colchicine-induced autotetraploid plant of $P$. plicatulum obtained at IBONE. It reproduces by sexual means, 
although it is self-sterile due to a self-incompatibility system, it produces seeds when crossed with another colchicine-induced tetraploid genotype (Sartor et al., 2009). The accession Allem and Vieira \# 1332 was brought to Corrientes in the early 1990's by pieces of rooted stolons. In previous studies, this accession was reported to be tetraploid with $2 n=40$ chromosomes (Pagliarini et al., 2001) which reproduces by facultative apomixis (data not shown).

Since $4 \mathrm{PT}$ is a sexual self-incompatible plant, crosses were made using this plant as a pistillate parent without emasculation and the apomictic $P$. oteroi was used as pollen donor. Several clones of $4 \mathrm{PT}$ were grown in pots in a greenhouse while $P$. oteroi was established in the field in a $4-\mathrm{m}^{2}$ plot. Inflorescences of $4 \mathrm{PT}$ were enclosed in glassine bags because they started flowering the next morning. Daily flowering of $4 \mathrm{PT}$ occurs on several spikelets of one inflorescence during the morning. Although anthesis takes few minutes to be completed in each spikelet, the time of daily blooming may elapse from about 9:00 a.m. to a little after 12:00 p.m. The flowering time in $P$. oteroi is fairly coincident with that of the 4PT strain of $P$. plicatulum. Pollen was collected from $P$. oteroi in glassine bags, dusted on exerted stigmata of $4 \mathrm{PT}$ several times during the daily blooming period and the pollinated inflorescences were kept in bags to prevent contamination with pollen of other sources. Because anthesis occurs during four to six consecutive mornings in one inflorescence, pollination was carried out daily until all spikelets flowered. Approximately one month later, the bagged inflorescence was harvested, the spikelets that formed grains were separated from the empty ones and were sown in the next spring. Seedlings were transplanted into small pots and then into the field.

\section{Hybrid origin of the progeny}

Because $4 \mathrm{PT}$ is a self-incompatible strain, all the plants obtained from 4PT $P$. plicatulum $\times P$. oteroi crosses were analyzed to confirm their hybrid origin, as occasional self-pollination might occur. Progeny tests were carried out using the random amplified polymorphic deoxyribonucleic acid (RAPD) analysis. The genomic deoxyribonucleic acid (DNA) was extracted from fresh leaves following traditional procedures (Dellaporta et al., 1983). The parents were analyzed to detect bands that were specific of the staminate parent $(P$. oteroi). Afterward, the surviving progeny was screened with several primers to investigate whether all individuals inherited at least some of the $P$. oteroi specific bands. Briefly, the screening was conducted by using 11 decamers (Set B) from Vancouver, Canada, to detect polymorphisms between parents. Then, the most informative primers were used to analyze the progeny to confirm whether all individuals inherited some bands that were specific of the male parent.

\section{Cytological studies}

The meiotic chromosome behavior of the male parent and some hybrids was analyzed to determine the cytological relationship of the two species. Young inflo- rescences of $P$. oteroi and several hybrids were fixed in a 5:1 solution of $100 \%$ ethanol-lactic acid and stored in $70 \%$ ethanol to study microsporogenesis. Pollen mother cells (PMC) were stained with $2 \%$ acetocarmine and observed with transmitted light or phase contrast microscopy. The meiotic behavior of the 4PT accession of $P$. plicatulum was analyzed previously (Sartor et al., 2009).

\section{Reproduction method}

For the flow cytometric seed screen (FCSS), Partec PAII (Münster, Germany) were used. Data were analyzed with FloMax 2.4 software. Preparation, measurement and interpretations of histograms were made as described by Matzk et al. (2000). The nuclei were stained with DAPI $(4 \alpha, 6$-diamidino-2-phenylindole). At least 3000 nuclei were analyzed for each sample. In most cases, 20 seeds were analyzed for each hybrid in order to assess the reproductive mode. $P$. plicatulum $4 \mathrm{PT}$ was used as internal standard. The protocol of Matzk et al. (2000) is suitable for either bulked or single seed analysis. As proposed by Greilhuber et al. (2005), the term C-value specifies the DNA content of the entire unreplicated haploid (gametic) chromosome complement of a given individual. Assessments of DNA content were made based on the G1 peaks of histograms. Seeds exhibiting histograms with peaks of DNA content of $2 \mathrm{C}$ and $3 \mathrm{C}$ indicated that the embryo was formed by syngamy of reduced egg cell and a reduced sperm nucleus $(n+n)$. The endosperm was made by the two reduced polar nuclei and the second sperm nucleus $[(n+n)+n]$. Conversely, a seed with 2C:5C DNA content ratio indicates that it was formed by parthenogenesis of an unreduced egg cell $(2 n+0)$ and pseudogamy, i.e., fertilization of two unreduced polar nuclei by a reduced sperm nucleus $[(2 n+2 n)+n]$. The FCSS was carried out by the seed-byseed analysis or by two seeds at a time. Therefore, it is possible to establish the proportion of sexual reproduction for a facultative apomictic individual.

Additionally, two hybrids, one classified as sexual and the other as apomictic by flow cytometry, were also analyzed by the ovary clearing technique to confirm their reproductive mode, as a general control. Mature ovaries collected at anthesis were clarified and observed with a differential interference contrast microcopy (DIC) following the same procedures that were used before (Novo et al., 2013). Because, in Paspalum, the sexual and the aposporous embryo sacs differ in their internal structure and structure, this technique allows assessing the reproductive mode by observing the type of embryo sac in mature ovules. Embryo sacs of the Polygonum type with an egg cell, two synergids, a central cell with two polar nuclei and a clump of antipodal cells were classified as meiotic sacs, typical of sexual reproduction. On the other hand, aposporous embryo sacs usually had one egg cell, a large round-shaped central cell with two polar nuclei, and complete lack of antipodal cells. This is considered the most distinctive feature of the Paspalum type of apospory, although eventually one or two synergids may be also present (Ortiz et al., 2013). 


\section{Fertility}

The effective fertility of $P$. oteroi cultivated in Corrientes, Argentina, and the fertility of some of the hybrids were analyzed by determining the proportion of spikelets that formed grain. Single inflorescences were bagged prior to blooming to know their seed set under self-pollination. Other inflorescences were bagged immediately after all their spikelets completed anthesis to establish the seed set under open-pollination condition.

\section{Results}

Four hundred and seventy-nine spikelets of sexual tetraploid 4PT $P$. plicatulum were dusted with pollen of $P$. oteroi in Feb. 2009 and only 23 formed caryopses. All of them were sown in a tray with sterilized soil in Aug. 2009. Twenty-two seedlings were obtained and transplanted into the field in Dec. 2009. Considerable phenotypic variation was observed among individuals of this family, mainly with regard to general plant vigor and growth habit. Several plants were smaller than both parents were and some of them died during the first year. Only 12 plants survived until the growing season 2010/2011. Growth habit varied from tufted to more or less decumbent individuals, some with branched stolons of variable length. Since bearing stolons is a characteristic trait of the pollen donor, all individuals bearing stolons or having a decumbent growth habit with multinode branches were primarily classified as hybrids. Indeed, none of the individuals exhibited the typical general phenotype of $P$. plicatulum, regardless of bearing multi-node branches. Most of them had morphological characteristics that were intermediate between parents as, for example, the number of racemes per inflorescences and the length of leaf blades. Spikelets of $P$. oteroi are typically pubescent, however, all individuals of the progeny that reached the flowering status, unexpectedly exhibited glabrous spikelets. In spite of the fact that the general morphological appearance suggested that all individuals originated by hybridization, a progeny test with RAPD markers was carried out to ensure that none of them originated by unexpected occasional selfpollination. Eleven decamers were screened to find polymorphism between parents. Four of them (Set 8: BC421, BC713, BC747 and BC767) were selected because they amplified clear bands that were specific to the male parent. Only 12 individuals of the progeny that were alive at the beginning of 2011 were considered for the RAPD analyses with the selected primers. All of these individuals amplified some of the specific bands of the male parent, $P$. oteroi, indicating that all of them originated by hybridization between the 4PT strain of $P$. plicatulum and the accession A\&V 1332 of $P$. oteroi.

Accession $\mathrm{A} \& \mathrm{~V} 1332$ of $P$. oteroi had $2 \mathrm{n}=4 \mathrm{x}=40$ chromosomes. The cytological analysis was carried out in $P$. oteroi and five interspecific hybrids. Fifty-four PMCs of $P$. oteroi, examined at diakinesis and first meiotic metaphase, showed chromosome configurations from univalents to quadrivalents with a mean of 1.3 univalents (I), 12.9 bivalents (II), 0.5 trivalents (III), and 2.8 quadrivalents (IV). Meiotic chromosome behavior in 101 PMCs of five interspecific hybrids showed a mean of 2.7 I, 16.1 II, 0.4 III, and 1.0 IV per cell (Table 1, Figure 1).

Table 1 - Meiotic chromosome associations at diakinesis and first metaphase in P. picatulum (4PT), P. oteroi (A\&V1332) and five of their interspecific hybrids. All are tetraploids with $2 n=4 x=40$ chromosomes.

\begin{tabular}{|c|c|c|c|c|c|c|}
\hline \multirow{2}{*}{ Species or hybrids } & \multirow{2}{*}{$\begin{array}{l}\text { No. of } \\
\text { plants }\end{array}$} & \multirow{2}{*}{$\begin{array}{l}\text { No. of } \\
\text { PMC }\end{array}$} & \multicolumn{4}{|c|}{ Average and range per cell } \\
\hline & & & I & $\|$ & III & IV \\
\hline P. plicatulum (4PT) * & 1 & 53 & $\begin{array}{c}0.1 \\
(0-1)\end{array}$ & $\begin{array}{c}14.2 \\
(6-18)\end{array}$ & $\begin{array}{c}0.1 \\
(0-1)\end{array}$ & $\begin{array}{c}2.8 \\
(1-7)\end{array}$ \\
\hline P. oteroi (A\&V1332) & 1 & 54 & $\begin{array}{c}1.3 \\
(0-5)\end{array}$ & $\begin{array}{c}12.9 \\
(4-18)\end{array}$ & $\begin{array}{c}0.5 \\
(0-2)\end{array}$ & $\begin{array}{c}2.8 \\
(0-8)\end{array}$ \\
\hline 4PT $\times$ A\&V1332 Hybrids & 5 & 101 & $\begin{array}{c}2.7 \\
(0-10)\end{array}$ & $\begin{array}{c}16.1 \\
(10-20)\end{array}$ & $\begin{array}{r}0.4 \\
(0-3)\end{array}$ & $\begin{array}{c}1.0 \\
(0-5)\end{array}$ \\
\hline
\end{tabular}

${ }^{*}$ From Sartor et al. (2009).

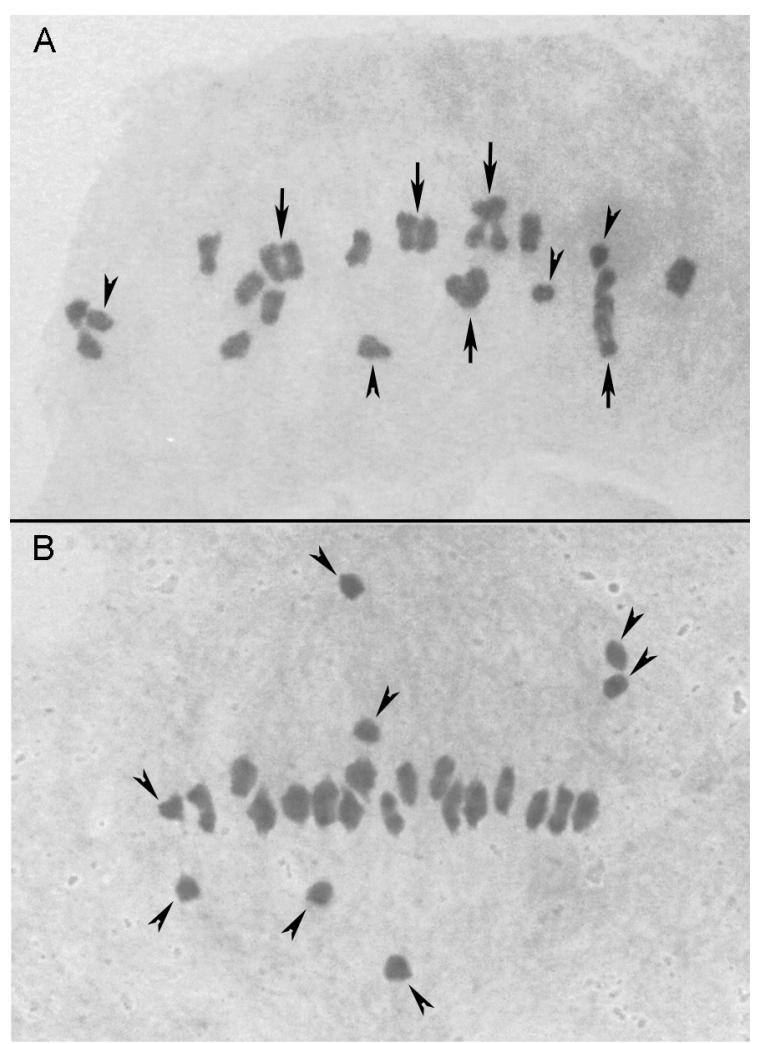

Figure 1- Microphotography of meiotic chromosome configurations: A, metaphase I in tetraploid $(2 n=40) P$. oteroi showing four univalents (arrow heads), eight bivalents, and five quadrivalents (arrows). B, metaphase I in a $P$. plicatulum $\times P$. oteroi interspecific hybrid with eight univalents (arrow heads) and 12 bivalents. Note that most univalents are placed in pairs, one in front of the other to opposite poles. 
Only 11 of the 12 surviving hybrids were analyzed for the reproductive mode by the FCSS protocol (Table 2). Because hybrid \# 4 failed to produce seed, it was not included in the FCSS analysis. Twenty caryopses were analyzed for each hybrid with the exceptions of hybrid \# 2 and hybrid \# 21 that produced very few seeds and only three and 10 caryopses were available for their analyses, respectively. The three caryopses of hybrid \# 2 exhibited histograms with $2 \mathrm{C}$ and $5 \mathrm{C}$ peaks corresponding with the DNA contents of the embryo and the endosperm tissues, respectively. This embryo:endosperm ratio in the DNA content indicated that the three seeds had been formed by apospory, parthenogenesis, and pseudogamy. Consequently, \# 2 was classified as apomictic. Since the seed sample was very small, it was not possible to ascertain whether this was an obligate or a facultative apomictic hybrid. Most seeds of hybrid \# 11 were formed by means of apomixis $(85 \%)$ and showed the typical 2C:5C embryo:endosperm ratio of DNA content. The remaining $15 \%$ developed from a meiotic embryo sac in which the double fertilization process occurred to form a seed with a $2 \mathrm{C}: 3 \mathrm{C}$ embryo:endosperm ratio characteristic of sexual reproduction. Therefore, hybrid \# 11 was a facultative apomictic plant. The other nine individuals were primarily classified as sexual-reproducing hybrids because all the analyzed seeds exhibited a $2 \mathrm{C}: 3 \mathrm{C}$ ratio for the DNA contents of the embryo and the endosperm.

Hybrids \# 8 and \# 11, which were classified by flow cytometry as sexual and facultative apomictic, respectively, were further analyzed by ovary clearing techniques as a general control purpose. Thirty-nine mature ovaries of hybrid \# 8 were analyzed. Thirty-three of them had ovules bearing a single embryo sac of the Polygonum type, while six ovules showed a deteriorating embryo sac or had no sac at all. Healthy-looking embryo sacs had an egg cell, two synergids, a bi-nucleate central cell, and a mass of antipodal cells at the chalazal end. This embryo sac structure is

Table 2 - Reproductive mode of 11 interspecific hybrids determined by flow cytometry according to the embryo:endosperm DNA content ratio in mature seeds. Abbreviations: Ap, apomictic; Fap, facultative apomictic; Sex, sexual.

\begin{tabular}{lcrrr}
\hline \multirow{2}{*}{ Hybrid } & $\begin{array}{c}\text { Number of } \\
\text { seeds analyzed }\end{array}$ & \multicolumn{2}{c}{$\begin{array}{c}\text { Embryo + (endosperm) DNA } \\
\text { Contents (C-values) }\end{array}$} & $\begin{array}{c}\text { Reproductive } \\
\text { mode }\end{array}$ \\
\cline { 3 - 3 } & & 2C+(3C) & 2C+(5C) & \\
02 & 3 & 0.0 & 100.0 & Ap \\
05 & 20 & 100.0 & 0.0 & Sex \\
06 & 20 & 100.0 & 0.0 & Sex \\
07 & 20 & 100.0 & 0.0 & Sex \\
08 & 20 & 100.0 & 0.0 & Sex \\
11 & 20 & 15.0 & 85.0 & Fap \\
13 & 20 & 100.0 & 0.0 & Sex \\
15 & 20 & 100.0 & 0.0 & Sex \\
19 & 20 & 100.0 & 0.0 & Sex \\
21 & 10 & 100.0 & 0.0 & Sex \\
22 & 20 & 100.0 & 0.0 & Sex \\
\hline
\end{tabular}

typical of sexual reproducing Paspalum species. From 36 mature ovaries analyzed for hybrid \# 11, 16 had ovules bearing one or rarely two aposporous embryo sacs, 15 had ovules with a single sexual sac of the Polygonum type, and five had unclassified deteriorate sacs. The aposporous sacs were easily distinguishable from sexual sacs by a conspicuous lack of antipodal cells. They had an egg cell and a large highly vacuolated central cell with two polar nuclei, while synergids were hardly noticeable, as it usually occurs at anthesis time in cleared ovules of Paspalum species. Thus, the embryological analysis through ovary clearing technique confirmed that hybrid \# 8 was sexual and hybrid \# 11 was a facultative apomictic one, although the expression of apomixis in this hybrid was higher (85\%) when analyzed in mature seed than when evaluated by the proportion of ovules bearing aposporous (16) versus sexual (15) embryo sacs, which scarcely exceeded $50 \%$.

Paspalum oteroi has poor seed set in Corrientes, Argentina, with a mean score of $28 \%$ of the spikelets filled with caryopses (Table 3). The low seed set might be a negative consequence of growing in an environment that probably has ecological differences with its natural habitat. Unfortunately, there is no solid information regarding the seed set performance of $P$. oteroi in its natural habitat in the Pantanal region. The $4 \mathrm{PT}$ genotype of $P$. plicatulum is self-sterile and a poor seed producer (seed set $25 \%$ ) when crossed with pollen of another chemically induced autotetraploid genotype of the same species (Sartor et al., 2009 and Table 3).

There was variation in fertility among the interspecific hybrids (Table 3). Considering the open-pollination conditions, the seed set varied among hybrids from completely sterile (hybrid \# 4) to seed productions that were approximately twice as much as either parent (hybrid \# 5 with $59 \%$, and \# 19 with $53 \%$ ). With the exception of hybrid \# 11 (30\%), seed set was very low for all hybrids under self-pollination condition.

Table 3 - Seed set (percentage of mature spikelets that formed caryopses) of sexual tetraploid P. plicatulum, apomictic tetraploid $P$. oteroi and seven interspecific hybrids.

\begin{tabular}{|c|c|c|c|c|}
\hline \multirow{2}{*}{$\begin{array}{l}\text { Parents and } \\
\text { hybrids }\end{array}$} & \multicolumn{2}{|c|}{ Self-pollination } & \multicolumn{2}{|c|}{ Open-pollination } \\
\hline & $\begin{array}{l}\text { Mature spikelets } \\
\text { analyzed }\end{array}$ & $\begin{array}{l}\text { Seed } \\
\text { Set }\end{array}$ & $\begin{array}{c}\text { Mature spikelets } \\
\text { analyzed }\end{array}$ & $\begin{array}{c}\text { Seed } \\
\text { Set }\end{array}$ \\
\hline & no. & $\%$ & no. & $\%$ \\
\hline P. plicatulum 4PT* & 3792 & 0 & 1535 & 25 \\
\hline P. oteroi A\&V1332 & 1827 & 17 & 1682 & 28 \\
\hline Interspecific Hybrids & & & & \\
\hline 4 & $\sim 500$ & 0 & $\sim 500$ & 0 \\
\hline 5 & 219 & 9 & 631 & 59 \\
\hline 6 & 228 & 6 & 636 & 26 \\
\hline 8 & 6178 & 0 & 7465 & 11 \\
\hline 11 & 329 & 30 & 316 & 43 \\
\hline 13 & 2112 & 0 & 424 & 5 \\
\hline 19 & 600 & 5 & 1975 & 53 \\
\hline
\end{tabular}




\section{Discussion}

Controlled crosses between a sexual reproducing, colchicine-induced autotetraploid genotype of $P$. plicatulum and a natural apomictic tetraploid strain of $P$. oteroi produced interspecific hybrids. The hybrid origin was effectively proven for 12 individuals while the remaining 10 individuals of the progeny died before their hybrid origin could be demonstrated. Thus, crossability of these species at tetraploid level was quite low. If we consider that a whole progeny of 22 individuals was recovered from 479 pollinated spikelets, crossability would be approximately $5 \%$. If we take into account only 12 surviving individuals after the first growing season, crossability is lower than $3 \%$.

In the female parent, the 4PT genotype of $P$. plicatulum is a sexual, self-incompatible, autotetraploid cytotype obtained by chromosome doubling of a co-specific diploid cytotype (Sartor et al., 2009). The meiotic chromosome configurations of the autotetraploid plant was described previously with a mean of 0.1 I, 14.2 II, $0.1 \mathrm{III}$, and 2.8 IV per PMC, and ranges of $0-1,6-18,0-1$, and 1-7, respectively (Sartor et al., 2009). We observed similar averages and ranges of meiotic chromosome configurations in the A\&V 1332 tetraploid accession of $P$. oteroi in comparison with the experimentally inducedautotetraploid female parent. The natural tetraploid $P$. oteroi also exhibits a high proportion of chromosomes in quadrivalent associations (average 2.8 IV, range 0-8 IV) remarkably similar to experimentally induced autotetraploid $P$. plicatulum, suggesting a natural autotetraploid origin for $P$. oteroi, although it has a fairly large number of univalent per PMC (average 1.3, range 0-5) in comparison with autotetraploid P. plicatulum or other autotetraploid species of the genus (Figure 1A). The average of $1.3 \mathrm{I}$ per PMC in $P$. oteroi may indicate that some chromosomal changes might have occurred since the species acquired the autopolyploid status.

The meiosis analysis in PMCs of five $\mathrm{F}_{1}$ interspecific hybrids showed a mean degree of bivalent chromosome pairing (16.1 per PMC) higher than either parent. Although the number of bivalents per PMC varied from 10 to 20, approximately 1/10 of PMC had 20 bivalents, while PMCs with 20 bivalents were observed neither in female nor in male parental plants. In addition, the relatively high number of univalent observed in the hybrids (mean 2.7 per PMC, range 0-10) may be more a consequence of precocious separation of bivalents during late metaphase rather than lack of chromosome pairing. Most unpaired chromosomes formed couples of univalents during the first meiotic metaphase, one in front of the other at both sides of the equatorial plate of the PMC (Figure 1B). The general meiotic chromosome behavior observed in the chemically induced autotetraploid female parent, in the natural tetraploid male parent, and in five of their interspecific hybrids, suggest that: tetraploid $P$. oteroi has an autoploid origin, although since then, a diploidization process might have slightly affected its meiotic behavior; the genome (the basic set of chromosomes) of autotetraploid $P$. plicatulum has some partial homology with the genome of natural autotetraploid $P$. oteroi, that is, they are homeologous genomes; consequently, the interspecific hybrids exhibit a cytological behavior of segmental allopolyploids. This new status of genome and particular chromosome combinations obtained after crosses between two different autotetraploids may be responsible for several genetic consequences: the high mortality observed among the hybrids, the wide range of variability of morphological characteristics, the unexpected patterns of inheritance of some traits such as the segregation for presence/absence of stolons, but also the variation in length and branching of the stolons or the absence of hybrids with pubescent spikelets. Another important genetic consequence was the extraordinary variation observed for seed production among the hybrids, from total sterility to higher seed set than either parent.

Crosses involved a sexual autotetraploid female parent (Sartor et al., 2009) and a facultative apomictic autotetraploid male parent. There is a large list of previous reports indicating that segregation for reproductive mode occurs among individuals of an $\mathrm{F}_{1}$ progeny when a sexual plant is crossed with an apomictic one in several species of Paspalum (e.g., Martínez et al., 2001; Stein et al., 2004; Aguilera et al., 2011; Novo et al., 2013). Consequently, segregation for the reproductive mode was also expected among the $P$. plicatulum $\times P$. oteroi hybrids. However, the proportion of apomictic plants observed in the progeny of $P$. plicatulum $\times P$. oteroi was surprisingly low. This low transmission rate of the apomictic trait may be attributed to the fact that $P$. oteroi is a facultative apomictic species. However, further analyses are required to know the real degree of apomictic reproduction in the facultative apomictic $P$. oteroi. Moreover, the effect of facultativeness of apomixis on the genetic transmission of this trait needs to be investigated in Paspalum, particularly in autopolyploid species.

We used flow cytometry to assess the reproductive mode of the hybrids and then we conducted embryological observations on one sexual and one facultative apomictic hybrid as controls. Embryology confirmed that hybrid \# 8 reproduced sexually while \# 11 was an effectively facultative apomictic hybrid. However, the level of apomictic reproduction of \# 11 was higher when it was assessed by flow cytometry in mature seeds (85\%) than when it was estimated by the proportion of aposporous embryo sacs observed in cleared ovaries collected at anthesis time (around $50 \%$ ). This increase of apomictic expression measured at the seed stage in relation to the scored expression during embryological stages seems to be a normal feature in Paspalum. In other species of the genus, it was already observed a drastic decline of the real expression of sexuality when it was assessed at different stages of development, from megagametogenesis through mature ovules, mature seeds, and the subsequent progeny. It seems that there is some biological 
disadvantages of sexual embryo sacs or sexually formed seeds in relation to apomictic development (Rebozzio et al., 2011; Hojsgaard et al., 2013).

In a previous report, concerning interspecific crosses between two autotetraploid species, $P$. simplex Morong and $P$. procurrens Quarin, it was observed that the stoloniferous culms of $P$. procurrens were inherited as a dominant character in the whole hybrid progeny (Hojsgaard et al., 2008). In our hybrid progeny of P. plicatulum $\times P$. oteroi, the stoloniferous culms of $P$. oteroi segregated and the growing vigor of the stolons varied among those hybrids that inherited the trait. Different genetic behaviors might be attributed to some differences in the cytogenetic background of the couple of species hybridized in each case. Paspalum simplex and $P$. procurrens are two autotetraploid species that share essentially one homologous genome (basic chromosome set) and the cytogenetic behavior of the hybrids closely resembles the cytogenetic patterns of autopolyploids. On the other hand, $P$. plicatulum and $P$. oteroi are also autotetraploid species, but the genome of $P$. plicatulum has only some partial homology with the genome of $P$. oteroi. Therefore, the cytogenetic behavior of the interspecific hybrids resembles, to some extent, the cytogenetic behavior of allopolyploids or segmental allopolyploids. This might affect the transmission and expression of some genes in the $\mathrm{F}_{1}$ interspecific progeny. A similar situation occurred with the inheritance of the pubescent-spikelet trait of $P$. chaseanum Parodi that was transmitted to the entire progeny when the species was hybridized with accession 4PT of $P$. plicatulum (Novo et al., 2013), while none of the hybrids has pubescent spikelets when we crossed the same $P$. plicatulum genotype with $P$. oteroi, a species also characterized by pubescent spikelets. Cytologically, $P$. plicatulum and $P$. chaseanum are autotetraploid, share homologous genomes and their interspecific hybrids show patterns of cytogenetic behavior very similar to autotetraploids while the $P$. plicatulum $\times P$. oteroi hybrids showed meiotic chromosome configurations of allotetraploids or segmental allotetraploids.

The great variability of seed set performance observed among the interspecific hybrids of $P$. plicatulum $\times P$. oteroi may well be a drastic genetic consequence of joining two homologous chromosome sets of $P$. plicatulum together with two homologous chromosome sets of $P$. oteroi that, in turn, have residual homeology with the two sets afforded by $P$. plicatulum to form the interspecific hybrids. The cytogenetics of the hybrids, resembling to some extent the cytogenetic behavior of allopolyploids or segmental allopolyploids, could likely be the biological cause for the seed set scores of some hybrids that exceeded twice the performance of either parent. On the other hand, some new particular genetic combinations obtained by hybridization may have negative effects on seed production of some specific hybrids. In addition, most interspecific hybrids showed much lower seed production scores following self-pollination than after open-pollination, suggesting that at least some elements of the self-incompatibility genetic system were inherited from the pistillate parent.

Our results show that it is possible to obtain interspecific hybrids between $P$. plicatulum and $P$. oteroi at the tetraploid level. In general, the hybrids showed less irregular meiotic chromosome behavior than either one of the autotetraploid parental species and some of them had a seed set far superior to that of their parents. Because most hybrids reproduce by sexual means, they could be used as female parents in backcrosses and in hybridizations with other species of the Plicatula group of Paspalum. Moreover, the low degree of self-fertility of several hybrids, combined with good seed set in cross-pollination, may allow hybridizations without previous emasculation. These results indicate that transferring genes between these species is a technically feasible tool in plant breeding programs for forage purposes. Vegetative stocks of all surviving hybrids will be kept at the University of the Northeast/Faculty of Agricultural Sciences, Corrientes, Argentina, and eventually at Embrapa Genetic Resources \& Biotechnology, Brasilia, Brazil, for further research or breeding programs.

\section{Acknowledgements}

We thank the facilities and support of University of the Northeast/Faculty of Agricultural Sciences (UNNE), Corrientes, Argentina, grant PI-A008-2013; National Council for Cientific Research and Technology (CONICET), Argentina, grant PIP-11220080101378; National Agency for Promotion of Science and Technology (ANPCYT), Argentina, grant PICT2011-1802. We also thank the facilities provided by Embrapa Genetic Resources \& Biotechnology (Embrapa - Cenargen), Brasilia, Brazil. Patricia E. Novo holds a CONICET research scholarship and received a research grant from UNNE. We also thank Dr. Henry A. Fribourg, Professor Emeritus of Crop Ecology, University of Tennessee, USA, for his kind review of the manuscript for English style and grammar.

\section{References}

Aguilera, P.M.; Sartor, M.E.; Galdeano, F.; Espinoza, F.; Quarin C.L. 2011. Interspecific tetraploid hybrids between two forage grass species: sexual Paspalum plicatulum and apomictic $P$. guenoarum. Crop Science 51: 1544-1550.

Allem, A.C.; Valls, J.F.M. 1987. Native Forage Resources in the Pantanal Region of Mato Grosso = Recursos Forrageiros Nativos do Pantanal Mato-Grossense. Embrapa/Cenargen, Brasília, DF, Brazil. (Documentos, 8). (in Portuguese).

Camastri Filho, J.A.; Costa Júnior, E.M.A. 1980. The GramaTio-Pedro (Paspalum oteroi) in the Pantanal Region of Mato Grosso = A Grama-Tio-Pedro (Paspalum oteroi) no Pantanal Matogrossense. Embrapa, Corumbá, MS, Brazil. (Comunicado Técnico, 4). (in Portuguese). 
Chase, A. 1929. Contributions from the Unites States National Herbarium: The North American Species of Paspalum. U.S. Government Printing Office, Washington, DC, USA. vol. 28, part 1.

Dellaporta, S.L.; Wood, J.; Hicks, J.B. 1983. A plant DNA minipreparation: version II. Plant Molecular Biology Reporter 1:19-21.

Forbes, I.; Burton, G.W. 1961. Cytology of diploids, natural and induced tetraploids, and intraspecies hybrids of bahiagrass, Paspalum notatum Flugge. Crop Science 1: 402-406.

Greilhuber, J.; Doležel, J.; Lysa, M.A.; Bennett, M.D. 2005. The origin, evolution and proposed stabilization of the terms 'genome size' and C-value to describe nuclear DNA contents. Annals of Botany 95: 255-260.

Hojsgaard, D.H.; Martínez, E.J.; Quarin, C.L. 2013. Competition between meiotic and apomictic pathways during ovule and seed development results in clonality. New Phytologist 197: 336-347.

Hojsgaard, D.H.; Schegg, E.; Valls, J.F.M.; Martínez, E.J.; Quarin, C.L. 2008. Sexuality, apomixis, ploidy levels, and genomic relationships among four Paspalum species of the subgenus Anachyris (Poaceae). Flora 203: 535-547.

Martinez, E.J.; Urbani, M.H.; Quarin, C.L.; Ortiz, J.P.A. 2001. Inheritance of apospory in Bahiagrass, Paspalum notatum. Hereditas 135: 19-25.

Matzk, F.; Meister, A.; Schubert, I. 2000. An efficient screen for reproductive pathways using mature seeds of monocots and dicots. The Plant Journal 21: 97-108.
Novo, P.E.; Espinoza, F.; Quarin, C.L. 2013. An apomictic tetraploid Paspalum chaseanum cytotype and its cytogenetic relationship with $P$. plicatulum (Poaceae): taxonomic and genetic implications. Australian Journal of Botany 61: 538-543.

Ortiz, J.P.A.; Quarin, C.L.; Pessino, S.C.; Acuña, C.A.; Martinez, E.J.; Espinoza, F.; Hojsgaard, D.H.; Sartot, M.E.; Cáceres, M.E.; Puplilli, F. 2013. Harnessing apomictic reproduction in grasses: what we have learned from Paspalum. Annals of Botany 112: 767-787.

Otero, J.R. 1937. Informations about Some Forage Plants = Informações sobre Algumas Plantas Forrageiras. Departamento Nacional da Produção Animal, Rio de Janeiro, RJ, Brazil. (in Portuguese).

Pagliarini, M.S.; Carraro, L.R.; Freitas, P.M.; Adamowski, E.V.; Batista, L.A.R.; Valls, J.F.M. 2001. Cytogenetic characterization of Brazilian Paspalum accessions. Hereditas 135: 27-34.

Rebozzio, R.N.; Sartor, M.E.; Quarin, C.L.; Espinoza, F. 2011. Residual sexuality and its seasonal variation in natural apomictic Paspalum notatum accessions. Biologia Plantarum 55: 391-395.

Sartor, M.E.; Quarin, C.L.; Espinoza, F. 2009. Mode of reproduction of colchicine-induced Paspalum plicatulum tetraploids. Crop Science 49: 1270-1276.

Stein, J.; Quarin, C.L.; Martínez, E.J.; Pessino, S.C.; Ortiz, J.P.A. 2004. Tetraploid races of Paspalum notatum show polysomic inheritance and preferential chromosome pairing around the apospory-controlling locus. Theoretical and Applied Genetics 109: 186-191. 